\title{
Drug reaction caused by clavulanate amoxicillin in dogs: report of two cases
}

\begin{abstract}
Pyoderma is a high incidence condition in canine dermatology. The treatment is based on cause control and appropriate antibiotic therapy. However, the use of drugs can lead to adverse reactions, which can compromise several organs and systems with several consequences that may progress to death. Pharmacodermia, a drug reaction expressed on the skin, is characterized as dose-dependent response correlated to excessive dosage. The dose independent responses are represented by individual reactions associated with allergic condition. Its occurrence is rare and poorly diagnosed in dogs due to similarity of cutaneous lesions to other dermatologic diseases. There is no specific diagnostic test, therefore the approach is based on animal history and clinical conditions. This manuscript reports two dogs with superficial pyoderma treated with antibiotic therapy consisted of beta-lactam associated with beta- lactamase inhibitor (clavulanate amoxycillin). After initiation of therapy the dogs developed worsening in the dermatological condition with papulous pustules and erythematous papules. Antibiotic therapy was discontinued and supportive care was established. It was possible to evidence remission and reestablishment of the cutaneous alterations of the animals after withdrawn of the drugs, condition compatible with pharmacodermia. The clinicians need be attentive about the risks and possibility of pharmacodermia after clavulanate-amoxicillin approach, which is routinely used in the small animal clinic.
\end{abstract}

Keywords: canine, beta-lactam, penicillin, pyoderma, antibiotic
Volume 3 Issue 5 - 2017

\author{
Mariana YH Porsani,' Monique Paludetti, ${ }^{2}$ \\ Camila S Pereira, ${ }^{3}$ Leandro Haroutune \\ Hassesian Galati, ${ }^{3}$ Marcio A Brunetto' \\ 'Department of Internal Medicine, FMVZ/USP, Brazil \\ ${ }^{2}$ Department of Veterinary Medicine, UFLA, Brazil \\ ${ }^{3}$ Department of Autonomous veterinarian, Brazil
}

Correspondence: Mariana YH Porsani, Av. Prof. Orlando Marquês Paiva, 87 - Butantã, 05508-900, São Paulo-SP, Brazil, Email mari.porsani@hotmail.com

Received: September 20, 2017 | Published: October 02, 2017

\section{Introduction}

The skin, the largest organ of the body, is the first defense line of the individual and is composed by physical chemical and microbiological barriers. ${ }^{1}$ These mechanisms alterations can predispose to colonization of bacteria and result in the development of pyoderma, cutaneous bacterial infection of high frequency in dogs., ${ }^{2,3}$ The pyodermas treatment is based on the elimination of the base cause and/or predisposing factors if it is possible, as well as antibiotic therapy. The antibiotics of choice are the broad-spectrum antibiotics as clavulanateamoxycillin, cefadroxil, cephalexin, clindamycin and lincomycin. ${ }^{1-3}$ The use of antibiotics can lead to adverse reactions concomitant or subsequent to treatment, alteration known as pharmacodermia. In human patients, is a high incidence disease, which are affected in about $10-20 \%$ of patients treated with antibiotics, being considered the fifth major cause of mortality. ${ }^{4,5}$ In veterinary medicine it is suggested that the casuistry may be underestimated, due to similarity with several skin diseases. ${ }^{1}$ In dogs pharmacodermia reports are scarce. In Brazil, cases of pharmacodermia have been reported in dogs after chemotherapy with carboplatin, ${ }^{6}$ cephalexin prescribed after ovariosalpingohisterectomy procedure ${ }^{7}$ and by excessive dose of antibiotic therapy with trimethoprim and sulfamadiazine. ${ }^{8}$ The pharmacodermia is characterized by allergic reaction with clinical alterations on the skin, mucous membranes and annexes, due to use of certain medicines. ${ }^{6,9}$ This clinical condition can lead to serious consequences such as anaphylactic reaction and death., ${ }^{4,8}$ Cutaneous manifestations are characterized by vesiculobullous eruptions, erythema multiforme, toxic epidermal necrolysis, bullous pemphigoid and others. ${ }^{1}$ The etiopathogenesis of pharmacodermia can be classified as dose-dependent, in which reactions are associated with drug dosage, or dose- independent, when it relates to individual immune response of the animal. ${ }^{4,5}$ The cause- dependent reaction is the most frequent and may have iatrogenic character. Their clinical correspond to adverse drug effects, being susceptible to any individual. ${ }^{5}$ Idiosyncrasy correlates only to genetic predisposition, being uncommon and unpredictable, their exact mechanisms have not been completely understood yet. Although it is known that in cases of drug reaction the immune system is activated similarly to allergic conditions. $^{5}$

The antibiotics are referred as the major cause of allergic reaction in human patients, among them penicillin has a high incidence ${ }^{10,5}$ The allergic reactions to this drug may involve type I, II, III and IV reactions. Type I is immunoglobulin E ( $\mathrm{IgE}$ ) mediated with fast onset and may cause pruritus, angioedema, bronchospasm and anaphylaxis. ${ }^{11,9,5}$ Type II is a non- immediate reaction and may involve severe complications of cytotoxicity, mediated by immunoglobulin M (IgM) and immunoglobulin G (IgG) with systemic alterations characterized by hemolytic anemia, thrombocytopenia and nephritis. ${ }^{4,9}$ Type III involves IgG and IgM, is non- immediate and cause skin rash, fever, lymphadenopathy and arthralgia..,5 Lastly, type IV represents late hypersensitivity and cause eczema, erythema multiforme and photodermatitis. ${ }^{11,9}$ The diagnosis of pharmacodermia is clinical, based on the patient report and clinical manifestations. ${ }^{1,5}$ In human patients the use of the skin tests as a diagnostic source was evaluated however this one presented low reliability with many false negative results to reactions due to penicillin use. ${ }^{12,13}$. Histopathologic exams can be performed in cases of severe lesions as support to differential diagnosis. ${ }^{5}$ The treatment consists of removing the causative agent and making the clinical support, through the control of secondary infections, pruritus and other changes that may be correlated to the case. ${ }^{1,5}$ Due to scarcity of relates about this severe condition in the small animal clinic, the present study aims to report two cases of canine patients with pharmacodermia after antibiotic therapy with 
clavulanate- amoxicillin. In order to guide and attempt the clinician about the associated changes as well as diagnosis and treatment.

\section{Case presentation}

\section{Case I}

It was attended on 06/03/2016 a female canine, Yorkshire Terries, six years old, 1.6 body weight, body condition score 4 on the ninepoint scale, as advocated by LAFLAMME ${ }^{14}$ with a prior diagnosis of atopy and trophallergic dermatitis. During the anamnesis, it was informed by the owner that the animal presented moderate intensity pruritus in the ventral region of the thorax and in the four limbs. At physical examination, it was observed hair thinning areas and periocular, interdigital, tarsal and carpal erythema. In the ventral thorax, it was evidenced meliceric crusts and epidermal collars. At cytological examination of the ontological cerumen it was observed Malassezia spp Antibiotic therapy was instituted using clavulanateamoxycillin at a dose of $22 \mathrm{mg} / \mathrm{kg}$ of body weight, orally, twice daily for 30 days and prednisone $1 \mathrm{mg} / \mathrm{kg}$, orally, once daily for five days. For topical use lotion based on $1 \%$ glycyrrhizin, $1 \%$ alpha bisabolol and $1 \%$ chlorhexidine was prescribed. The animal returned to attendance 3 days after the beginning of pharmacologic therapy, being informed by the owner that two days after starting the drugs new generalized lesions were observed in the abdomen. At physical examination, it was evidenced involvement of the glabrous area in the ventral abdomen, ventral thorax and tarsus. Being this a erythrodermic condition of disseminated multifocal distribution (Figure1). Sometimes coalescing with papule- pustular lesion, it was suggested an acute generalized exanthematouspustulosis condition (Figure 2). At laboratorial exams, there were no significant changes. By exclusion it was suggested pharmacodermia diagnosis. The antibiotic therapy was discontinued, maintaining only oral prednisone. The topical treatment was modified for baths with topical solution based on ceramides complex and fatty acids $0.5 \mathrm{~g}$, monosaccharides $1.5 \mathrm{~g}$ and polyglycosides $1 \mathrm{~g}$, each fourdays in the abdominal region. There was remission of the lesions progressively.

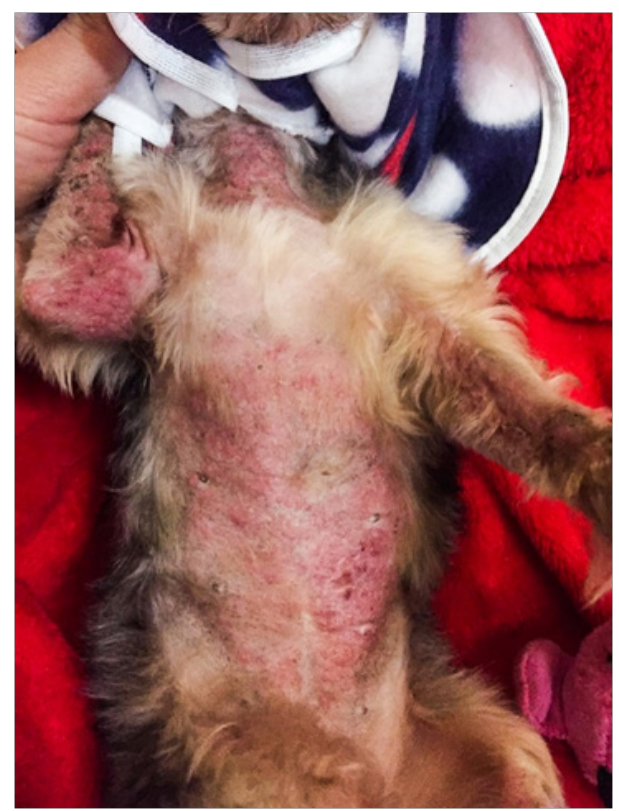

Figure I Erythrodermic condition with involvement of the glabrous area in the ventral abdomen, ventral thorax and tarsus.

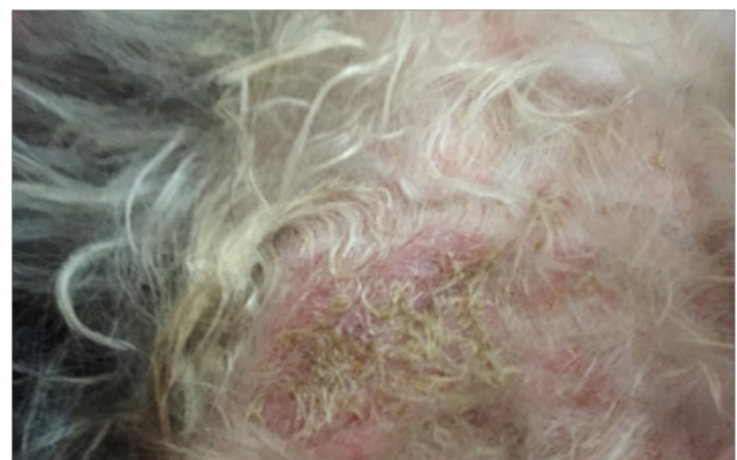

Figure 2 Papule pustular lesion in the ventral neck area after treatment with clavulanate- amoxycillin.

\section{Case II}

It was attended on 10/05/2016 a female canine, approximately 6 months old, mixed breed, $10 \mathrm{~kg}$ body weight, body condition score 5 on the nine-point scale, as advocated by LAFLAMME ${ }^{14}$ nondomiciled, with complaints of multiple lesions over the body and intense pruritus. At physical examination, it was noticed hair thinning area around the back of the animal, alopecia, papule pustular lesions, erythema, epidermal collars and meliceric crusts. It was realized a skin scraping, which was not showed changes worth of note. Therapy with ivermectin at a dose of $0.5 \mathrm{mg} / \mathrm{kg}$ of body weight, each sevendays and clavulanate- amoxycillin at a dose of $22 \mathrm{mg} / \mathrm{kg}$ of body weight twice daily, was instituted for 30 days. The animal returned to attendance after eight days. It was informed by the owner worsening of the lesions and intense pruritus starting three days after the institution of antibiotic therapy. Physical examination revealed a new lesion pattern in the lower back, with widespredalopecia, permeated by lesions of morbilliform pattern, papulous erythema, with epidermal detachment areas, maculopapular eruption, exulceration and eroded ulceration with hematic scabs (Figure 3). By exclusion it was suggested pharmacodermia diagnosis. The antibiotic therapy was discontinued, maintaining ivermectin administration. As complementary therapy, as instituted cephalexin antibiotic therapy at a dose of $30 \mathrm{mg} / \mathrm{kg}$ of body weight, orally, twice daily for 30 days and prednisone $1 \mathrm{mg} / \mathrm{kg}$ body weight, orally, once daily for seven days and analgesics dipyrone $25 \mathrm{mg} / \mathrm{kg}$ body weight orally twice daily and tramadol hydrochloride $2 \mathrm{mg} / \mathrm{kg}$ orally twice daily for four days. After the change of therapy was a total remission of the lesions in two weeks.

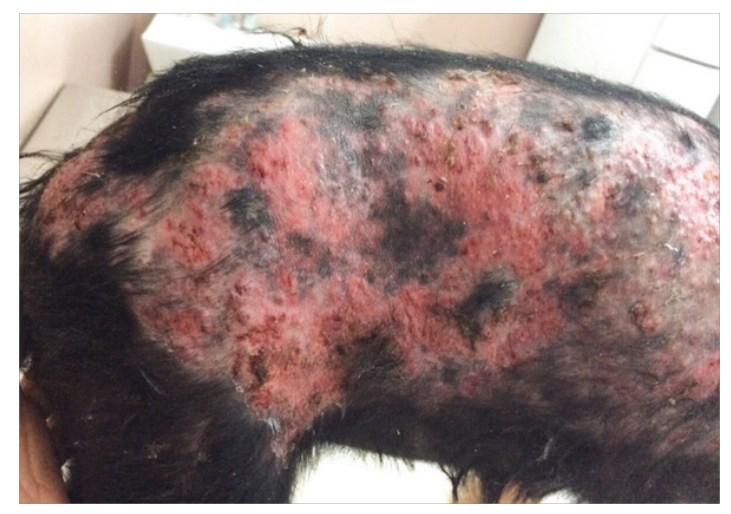

Figure 3 Widespred alopecia, permeated by lesions of morbilliform pattern, papulous erythema, exulceration and eroded ulceration with hematic scabs in the lower back, after treatment of clavulanate- amoxycillin. 


\section{Discussion}

Pyodermas is a high incidence condition in dogs, being the treatment based on the broad- spectrum antibiotic use., ${ }^{2,3}$ In the reported animals antibiotic therapy with clavulanate- amoxycillin was chosen, one of the first antibiotic of choice for this condition, ${ }^{2,3}$ using the recommended dose for the specie 12.5 to $25 \mathrm{mg} / \mathrm{kg}$ of body weight orally twice daily. ${ }^{15}$ Pharmacodermia can occurs in any patient, being considered a diagnostic challenge due to similarity of clinical changes to other cutaneous affections ${ }^{1}$ The causes of this condition involve dosing errors as related by Trapp et al. ${ }^{8}$ in which after antibiotic therapy use with sulfadizine and trimetropin at excessive dosage, the canine was affected by ulcerative dermatitis with areas of necrosis. Another cause is individual reaction by idiosyncrasy as in the present study and as referred by Balda et al. ${ }^{6}$ in which cutaneous changes were noticed after the introduction of drugs at correct dosages. ${ }^{9,5}$ Evidence in human patients shows a hypersensitivity condition secondary to use of beta-lactam antibiotics, with clinical manifestation that may occur immediately or days after drug use. ${ }^{1,5,10}$ In many cases, the reactions are expressed in the skin and can be characterized by acute generalized exanthematouspustulosis. ${ }^{5,16}$ The pruritus is a common but variable manifestation seen only in the first related animal. ${ }^{1,5}$ Some factors can be considered predisposing to pharmacodermia condition. Human reports shown a higher prevalence of this affection in atopic and female patients. ${ }^{1,12}$ Although, the present study is related to canine species, the susceptibility was also observed. For the diagnosis, should be performed a thorough physical exam, a hemogram and detailed anamnesis, in which the owner must be questioned about the period between the beginning of the drug treatment and the clinical manifestations. ${ }^{5,9} \mathrm{~A}$ hemogram should be realized in order to exclude complications that may be associated to pharmacodermia such as hemolytic anemia and thrombocytopenia. ${ }^{5}$ In the animals reported the diagnostic was based on clinical findings and time of lesion evolution after appeared days after the beginning of antibiotic administration, since there was not allergic tests for clavulanate- amoxycillin in clinical practice. The treatment is based on discontinuing the therapy and if necessary replacing the drug with another pharmacological class. ${ }^{1,4,7}$ The glucocorticoid use or anti histamine may be indicated depending on the type of clinical manifestations presented. However, its use is controversial and it is not indicated in epidermal necrolysis cases. ${ }^{5,9}$ In both cases reported, after discontinuation of clavulanateamoxycillin and immunosupressant use, there was a significant improvement of clinical condition. Due to fast reestablishment of the animals after discontinuation of the drug, the histopathological exam was not necessary. Obteining an early diagnosis is necessary to avoid severe consequences or even the death of the patient. ${ }^{5,7}$ It is important to take into account the history of the animal in order to prevent another prescription of the same drug, which may have more serious consequences. It is worth noting that patients with hypersensitivity to penicillin may present cross- react with other beta- lactams. ${ }^{13,17}$

\section{Conclusion}

The pharmacodermia can intrigue the veterinarian due to the nonspecific lesions and the lack of a fast and accurate diagnostic method. It is important to the clinician to be attempt to appearance of clinical changes after the introduction of any drug, since any medicine can lead to adverse reaction. The search of the clinical history along with thorough physical exam should be performed for the diagnosis of this condition in order to avoid serious consequences, which may lead the animal to death.

\section{Acknowledgements}

None.

\section{Conflict of interest}

The author declares no conflict of interest.

\section{References}

1. Larsson CE, Lucas R. Farmacodermia. In: Larsson CE, Lucas R, editors. Tratado de medicina externa: dermatologia veterinária. 1st ed. São Caetano do Sul, Brazil; 2016. p. 675-700.

2. Beco L, Guaguere E, Méndez CL, et al. Suggested guidelines for using systemic antimicrobials in bacterial skin infections:part 2-antimicrobial choice, treatment regimens and compliance. The Veterinary record. 2013;172(6):156-160

3. Summers JF, Brodbelt DC, Forsythe PJ, et al. The effectiveness of systemic antimicrobial treatment in canine superficial and deep pyoderma: a systematic review. Vet Dermatol. 2012;23(4):305-329.

4. Arunvikram K, Mohanty I, Sardar KK, et al. Adverse drug reaction and toxicity caused by commonly used antimicrobials in canine practice. Veterinary World. 2014;7(5):299-305.

5. Voie KL, Campbell KL, Lavergne SN. Drug hypersensitivity reactions targeting the skin in dogs and cats. J Vet Intern Med. 2012;26(4):863874.

6. Balda AC, Vieira JF, Gomes RR, et al. Farmacodermia após uso de carboplatina em cão: relato de caso. Revista de Educação Continuada em Medicina Veterinária e Zootecnia do CRMV-SP. 2014;12(2):36-36.

7. Aleixo GAS, Coelho OC, Andrade, et al. Farmacodermia em um cão após administração de antibióticos do grupo betalactâmico:relato de caso. Arq Bras Med Vet Zootec. 2010;62(6):1526-1529.

8. Trapp SM, Neta JH, Okano W, et al. Farmacodermia associada a reações sistêmicas em um cão Pinscher Miniatura medicado com a associação de trimetoprim e sulfadiazina. Arquivos de Ciências Veterinárias e Zoologia da UNIPAR. 2005;8(1):79-85.

9. Silva LM, Roselino AMF. Reações de hipersensibilidade a drogas (farmacodermia). Medicina Ribeirao Preto. 2003;36(2/4):460-471.

10. Bigby M. Rates of cutaneous reactions to drugs. Arch Dermatol. 2001;137(6):765-770.

11. Schnyder B, Pichler WJ. Skin and laboratory tests in amoxicillinand penicillin induced morbilliform skin eruption. Clin Exp Allergy. 2000;30(4):590-595.

12. Apter AJ, Schelleman H, Walker A, et al. Clinical and genetic risk factors of self-reported penicillin allergy. $J$ Allergy Clin Immunol. 2008;122(1):152-158

13. Bousquet PJÃ, Pipet Ã̃, Demoly PÃ. Oral challenges are needed in the diagnosis of $\mathrm{b}$-lactam hypersensitivity Clinical and Experimental Allergy. Clinical and Experimental Allergy. 2007;38:185-190.

14. Laflamme DP. Development and validation of a body condition score system for dogs. Canine practice. 1997;22:10-15.

15. Lloyd DH, Carlotti DN, Koch HJ, et al. Treatment of canine pyoderma with co-amoxyclav: a comparison of two dose rates. Vet Rec. 1997;141(17):439-441.

16. Belda J, Ferolla W. Acute generalized exanthematouspustulosis (AGEP). Case report. Revista do Instituto de Medicina Tropical de São Paulo. 2005;47(3):171-176.

17. Maddison JE. Adverse drug reactions: report of the Australian Veterinary Association Adverse Drug Reaction Subcommittee, 1992. Australian veterinary journal. 1992;69(11):288-291. 